\title{
RESPONSE OF HYPOTHYROIDISM TO HOMEOPATHIC TREATMENT: A REPORT OF THREE CASES
}

\author{
SOUMYABRATA DOGRA ${ }^{1 *}$, PRATIMA MANDAL ${ }^{2}$ \\ ${ }^{1}$ Department of Community Medicine, Kharagpur Homoeopathic Medical College and Hospital, Kharagpur, West Bengal, India. \\ ${ }^{2}$ Department of Obstetrics and Gynaecology, Kharagpur Homoeopathic Medical College and Hospital, Kharagpur, West Bengal, India. \\ Email: dr.soumyasimilima@gmail.com
}

Received: 03 July 2020, Revised and Accepted: 14 July 2020

\section{ABSTRACT}

Objectives:Hypothyroidism is a disease in which the thyroid gland does not produce enough thyroid hormone.It is the second most common endocrine disorder among women.Common causes are autoimmune disease such as Hashimoto's thyroiditis, surgical removal of the thyroid and radiation therapy.Symptoms of Hypothyroidism include weight gain, alteration in cognition, fatigue, infertility and menstrual abnormalities.Thyroid stimulating hormone is highly sensitive to thyroid dysfunction and is used to evaluate thyroid disorders.Monotherapy with Levothyroxine is the standard for treating hypothyroidism in the conventional method.Apart from coventional method of treatment homoeopathy also has a scope in the treatment of hypothyroidism.

Methods: This is a series of three cases which presented with symptoms of Hypothyroidism thoroughly evaluated and treated with constitutional homoeopathic medicine in a variable period of time.Assesment of thyroid stimulating hormone was done to see the improvement in the cases .

Results: A marked improvement in the clinical symptoms as well as the pathological report was observed.

Conclusion: This case series shows that Homoeopathic intervention can be used in the treatment of Hypothyroidism.

Keywords: Hypothyroidism, Homeopathy, Homeopathic treatment.

(C) 2020 The Authors. Published by Innovare Academic Sciences Pvt Ltd. This is an open access article under the CC BY license (http://creativecommons org/licenses/by/4. 0/) DOI: http://dx.doi.org/10.22159/ijms.2020.v8i5.38924

\section{INTRODUCTION}

Hypothyroidism is characterized by a broad clinical spectrum ranging from an overt state of myxedema, end-organ effects, and multisystem failure to an asymptomatic or subclinical condition with normal levels of thyroxine and triiodothyronine and mildly elevated levels of serum thyrotropin. The prevalence of hypothyroidism in the developed world is about 4-5\% [1].

The prevalence of hypothyroidism in India is $11 \%$, compared with only $2 \%$ in the United Kingdom (UK) and $4.6 \%$ in the United States of America (USA). Compared with coastal cities (e.g., Mumbai, Goa, and Chennai) and cities located inland (e.g., Kolkata, Delhi, Ahmedabad, Bangalore, and Hyderabad) have a higher prevalence (11.7\% vs. 9.5\%) The highest prevalence of hypothyroidism (13.1\%) is noted in people aged between 46 and 54 years, with people aged between 18 and 35 years being less affected (7.5\%) [2].

In India, hypothyroidism was usually categorized under the cluster of iodine-deficient disorders which were represented in terms of total goiter rates and urinary iodine concentrations, typically assessed in school-aged children [3]. In 2004, the World Health Organization assessment of global iodine status classified India as having "optimal" iodine nutrition, with a majority of households $(83.2 \%$ urban and $66.1 \%$ rural) now consuming adequate iodized salt [4]. Hypothyroidism is a common but underdiagnosed disorder because of its non-specific clinical presentations [5]. Hypothyroidism presents with a myriad of subtle and non-specific manifestations such as weight gain, poor concentration, depression, fatigue, muscular weakness, menstrual irregularities, and short stature. Some features of hypothyroidism are more suggestive, such as dryness of skin, proximal myopathy, constipation, cold intolerance, and dry brittle hair. The presentation of hypothyroidism depends on various factors, such as age and sex. The other common presenting features were constipation, weight gain, and carpal tunnel syndrome. Sleep apnea, snoring, menorrhagia, dysphagia, and dysarthria were seldom present [6]

This is a report of three cases of different age groups suffering from hypothyroidism. All three cases are managed with homeopathic medication and regular follow-up with proper management. Apart from conventional medication, alternative therapy (homeopathy) is warranted for a better and gentle treatment regimen in case of hypothyroidism.

\section{CASE 1}

A 45-year-old women presented with exertional dyspnea, weakness, and hair fall for the past 3 months. She presented with these symptoms, and the symptoms developed gradually.

She has a history of nasal polyps at the age of 10 . She gradually became obese, now weight is $73 \mathrm{~kg}$.

In family history, her father is having neurofibromatosis.

Generals (mental and physical)

The woman is very sensitive to cold which causes enlargement of the cervical lymph nodes. Thermal relation is chilly.

She perspires profusely, especially at the head.

She has a good appetite. She has a good desire to take eggs and sweets. During pregnancy, she had a special desire for muds, spice, ash, etc. Her bowel habit is not regular and stool is constipated. She is clumsy and falls easily.

Mentally, she has very much anxiety about her health, thinks it is not curable and depressed. Awkwardness is there. Confusion of mind and during conversation answers very slowly. 
Repertorization

Repertorization is done with the help of Kent's repertory using Hompath classic (Table 1).

\section{Prescription}

Calcarea carbonica 200, 2 doses in $15 \mathrm{~mL}$ distilled water for consecutive on investigation TSH level was higher (Fig. 1) 2 days, was prescribed on
June 5, 2019, according to symptom totality after careful repertorization and consultation with Materia Medica.

Placebo in the form of aqua dist. (60 mL). Once-daily (2 mL) for 1 month. Then, consecutive three follow-ups were done and placebo given. The patient improved gradually physically and mentally, along with reaching normal TSH level.

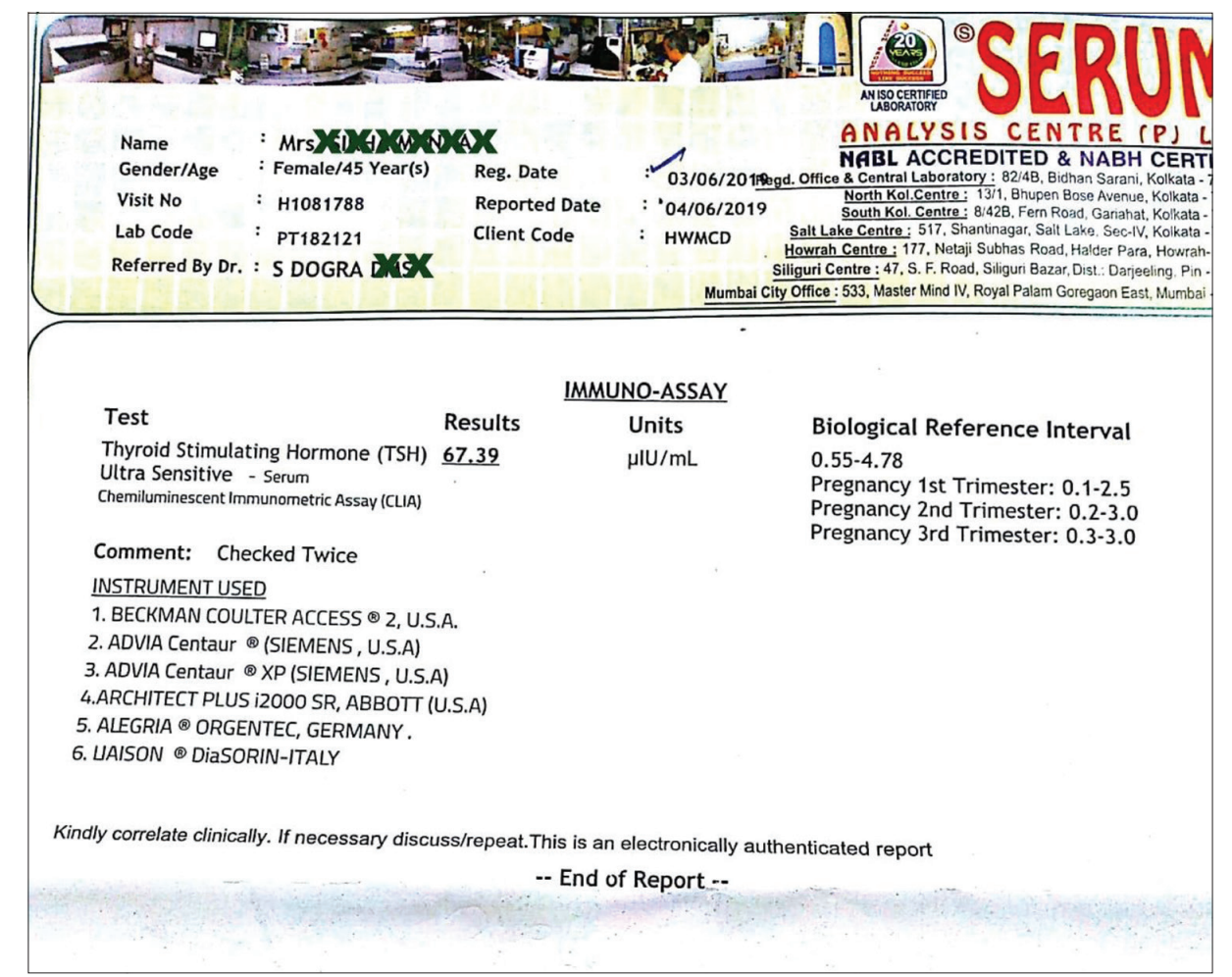

Fig. 1: Examination of TSH (before treatment)

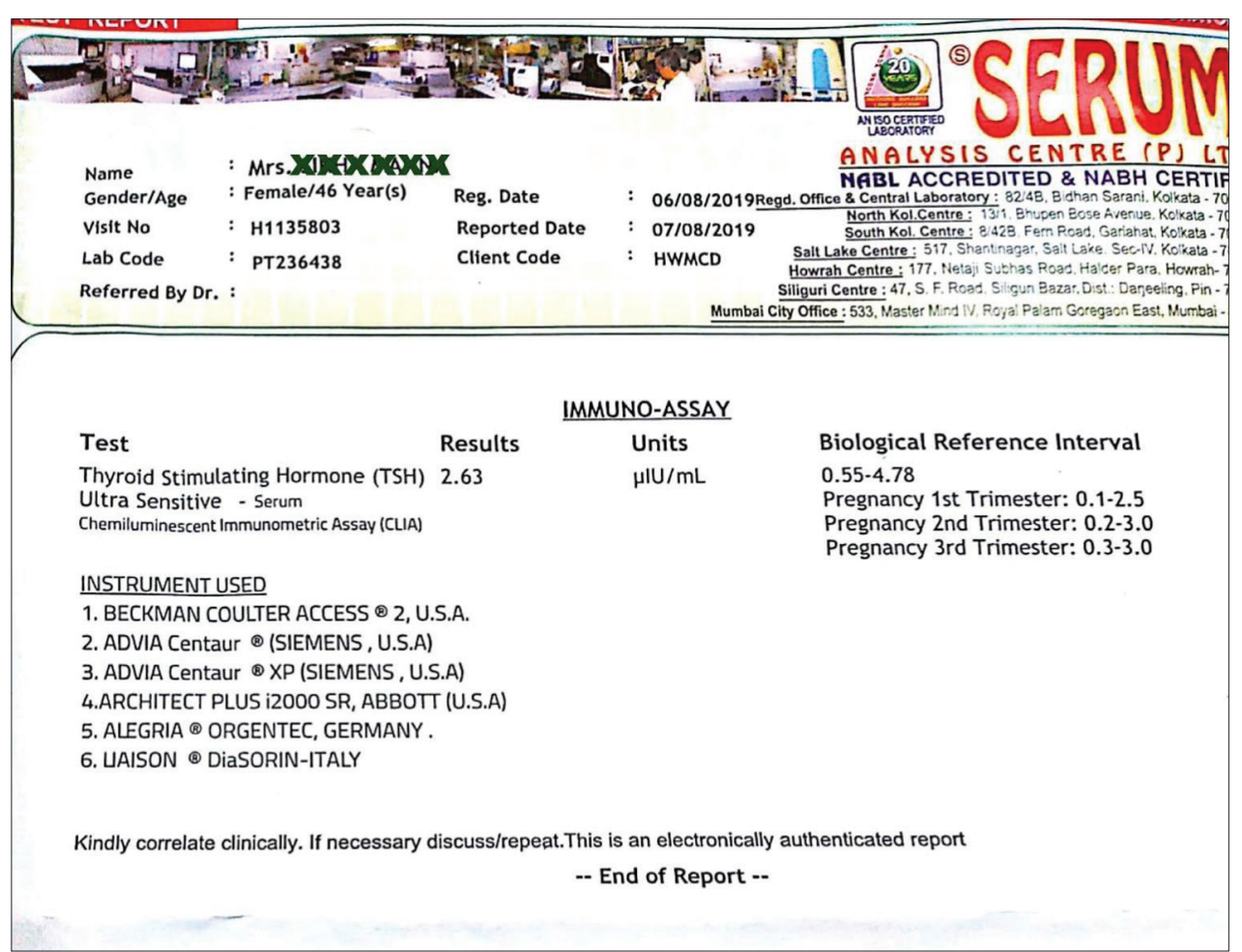

Fig. 2: Examination of TSH (after treatment) 
Follow-ups

Thirty-two days after the first prescription. Exertional dyspnea improved slightly. All other symptoms remain the same as before. No additional or new symptoms found. Placebo given.

Sixty-eight days after the first prescription. TSH level found normal (Fig. 2). Mental anxiety and other physical generals also improved. Placebo given.

Ninety-two days after the first prescription. The patient feels better. No new symptoms appear. Placebo given.

\section{CASE 2}

A 42-year-old woman came with hoarseness of voice and debility, no pain in the throat, and no history of voice strain. The patient felt gradually her voice become husky. She was associated with debility and hair loss and roughness of skin for past 3 months.

In history, she had repeated attacks of dysentery. She also developed styes each year during puberty. In family history, the mother is suffering from anal fistula, grandfather is suffering from COPD.

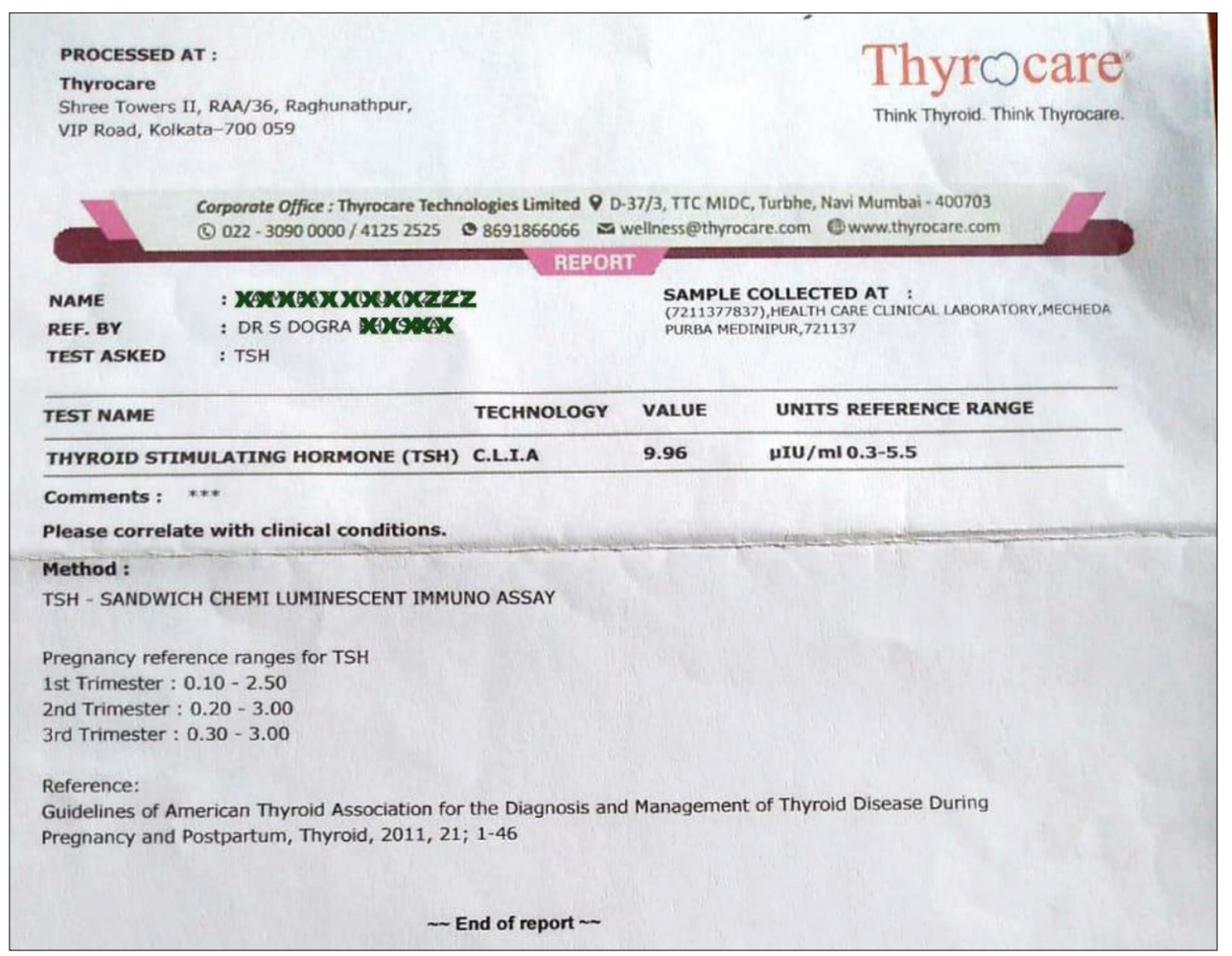

Fig. 3: Examination of TSH (before treatment)

Table 1: Repertorization

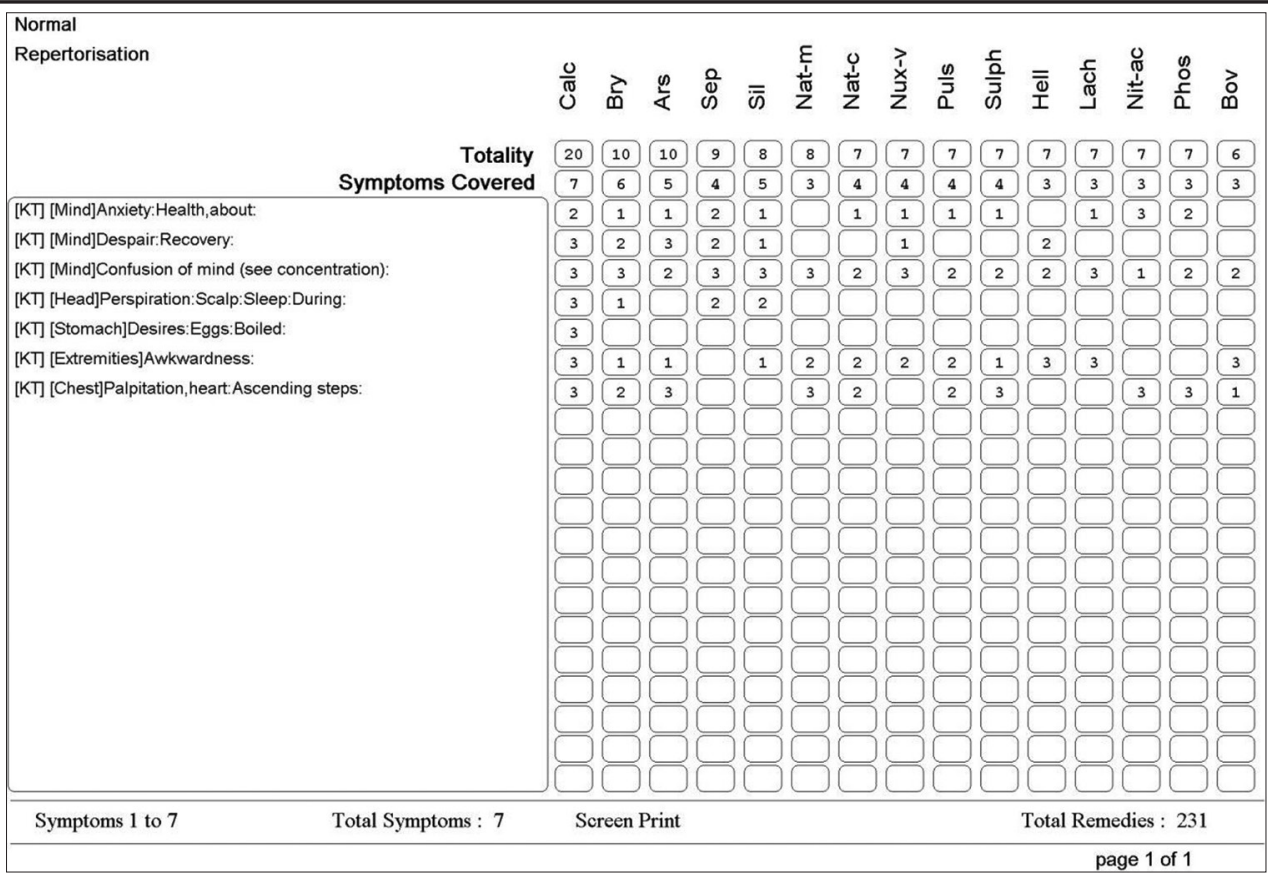


Generals (physical and mental)

The women are gentle, mild, and weeping when describing her complaints. Anemic become easily exhausted. Thermally, the patient is chilly but prefers open air. Appetite is diminished, thirstless takes only 3 or 4 glasses of water in a day. Any kind of fried, oily, and rich food makes abdominal discomfort heartburn, eructation tasting of food taken long before. Sweating has an offensive smell. Stool is irregular and constipated. Sleep is very much unrefreshing. After getting up in morning, she feels drowsy and not refreshed cannot be able to concentrate on any work.

\section{Repertorization}

Repertorization done through Kent's repertory using Hompath Classic (Table 2).

\section{Prescription}

Pulsatilla nigricans, 2 doses in $15 \mathrm{~mL}$ distilled water for consecutive on investigation TSH level was higher (Fig. 3) 2 days, was prescribed on June 5, 2019, according to symptom totality and after careful repertorization and consultation with Materia Medica.

Placebo in the form of aqua dist. ( $60 \mathrm{~mL}$ ). Once-daily ( $2 \mathrm{~mL}$ ) for $1 \mathrm{month}$. Then, consecutive three follow-ups were done and placebo given. The patient improved gradually physically and mentally, along with reaching normal TSH level.

\section{Follow-ups}

Thirty-four days after the first prescription. Exertional dyspnea improved slightly. All other symptoms remains the same as before. No additional or new symptoms found. Placebo given.

Sixty-four days after the first prescription. TSH level found normal (Fig. 4). Mental anxiety and other physical generals also improved. Placebo given.

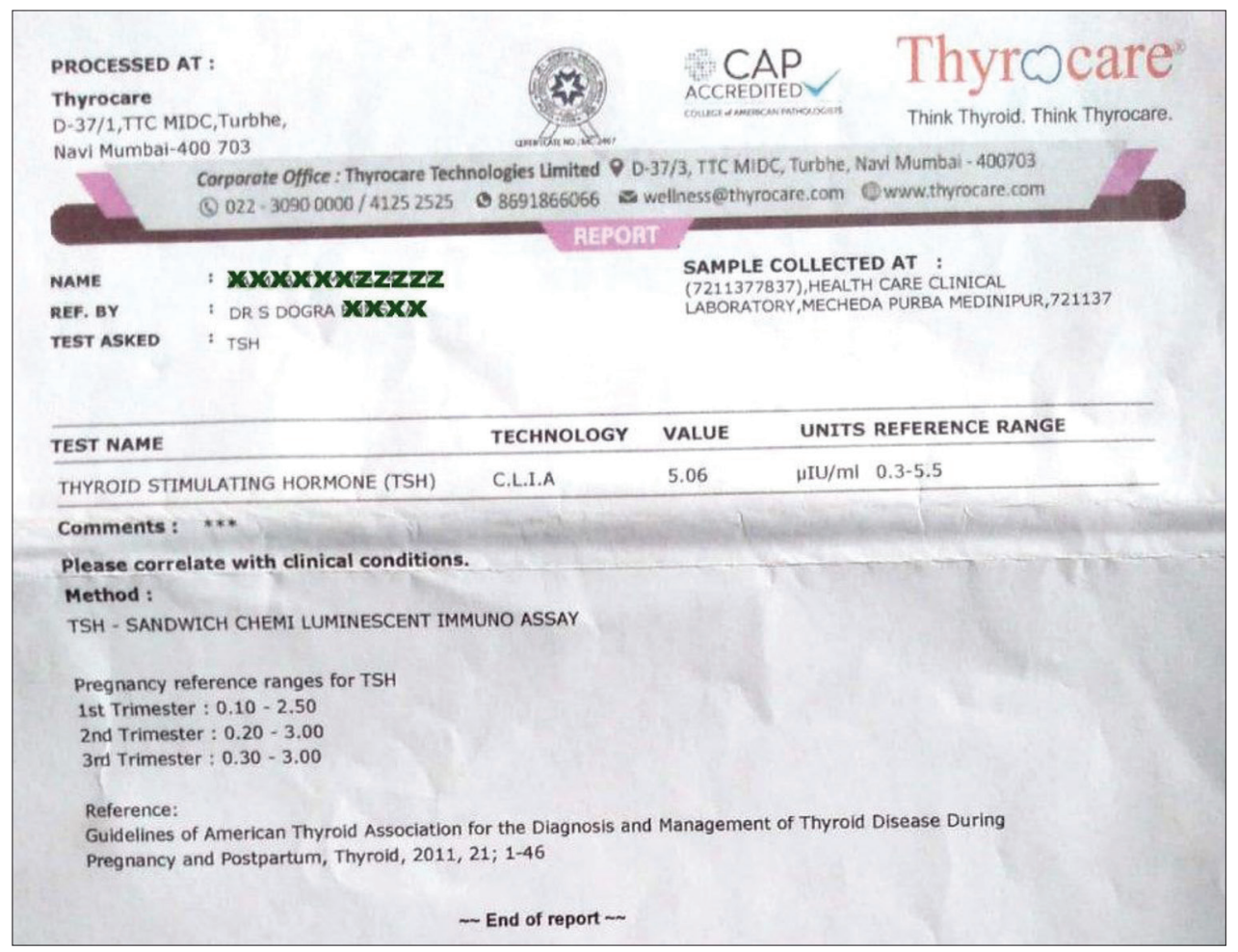

Fig. 4: Examination of TSH (after treatment)

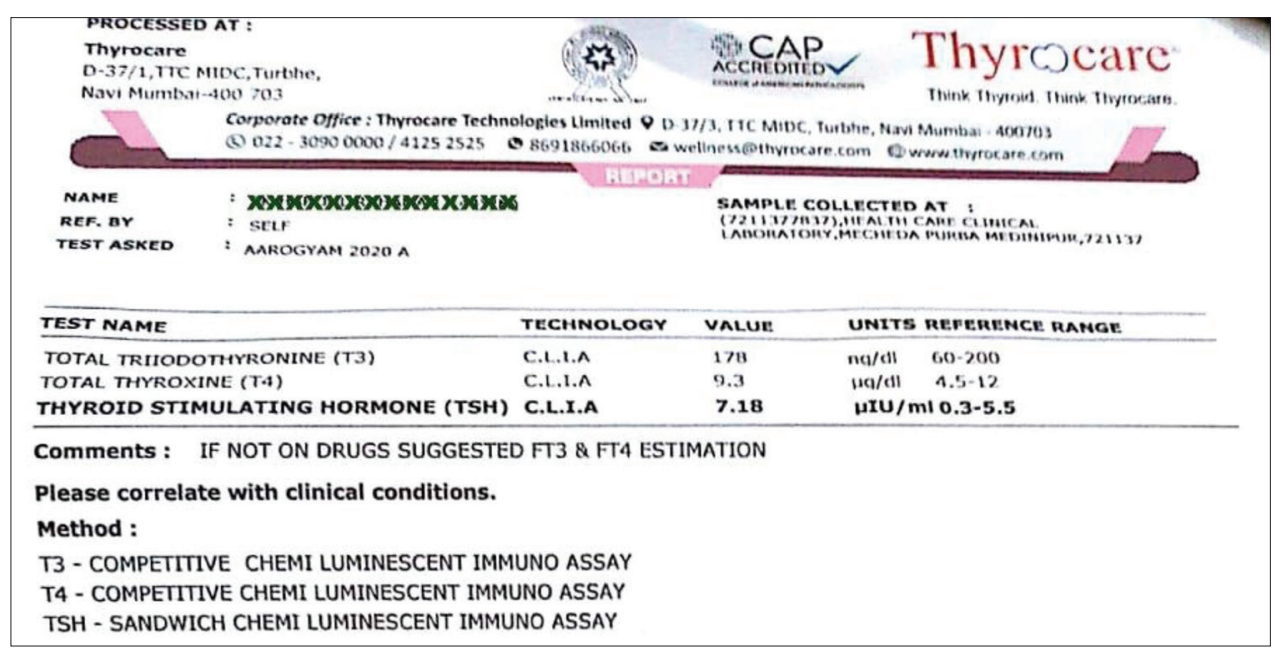

Fig. 5: Examination of TSH (before treatment) 
Table 2: Repertorization

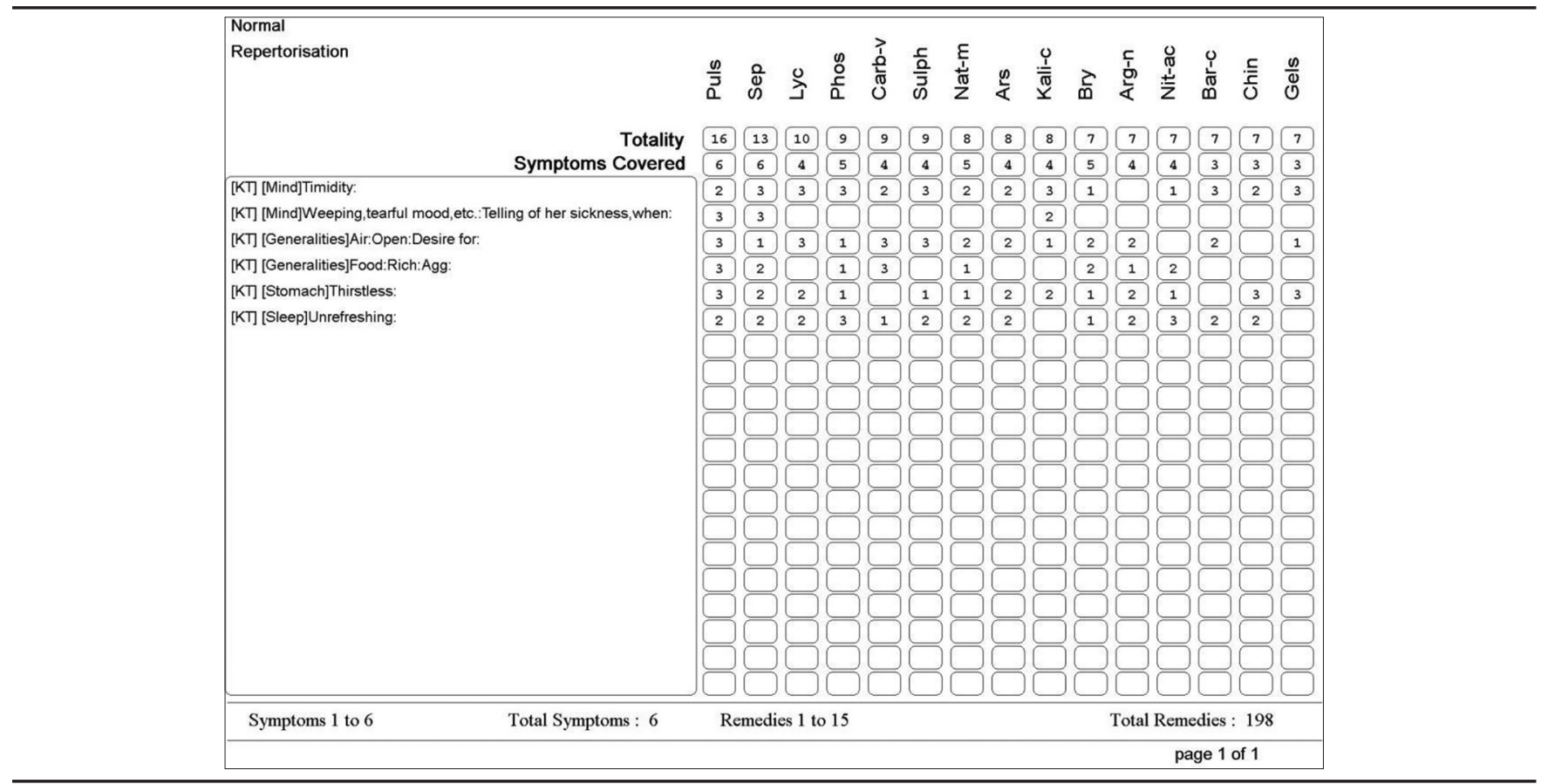

Table 3: Repertorization

Normal
Repertorisation
Symptoms Covered

Ninety-six days after the first prescription. The patient feels better. No new symptoms appear. Placebo given.

\section{CASE 3}

A 44-year-old man presented with lethargy, sleepiness throughout the day, and lack of concentration in work for the past 2 months.

He has a history of bleeding piles. In family history, his father is suffering from asthma and mother is suffering from allergic rhinitis.

\section{Generals (mental and physical)}

He is tall and slim. He cannot tolerate hunger. Takes his meal in a fixed time. Very much found of sweets. Thirstless, ugliness, and uncleanliness are demonstrated by his demeanor. Perspiration is offensive. During sleep, he rests his arm on forehead, very much aversion to take regular bath.

\section{Repertorization}

Repertorization is done with the help of Kent's repertory using Hompath Classic (Table 3).

\section{Prescription}

Sulphur 200, 2 doses in $15 \mathrm{~mL}$ distilled water for consecutive 2 days, on investigation TSH level is higher (Fig. 5) was prescribed on March 26, 2020 , according to symptom totality and after careful repertorization and consultation with Materia Medica. 


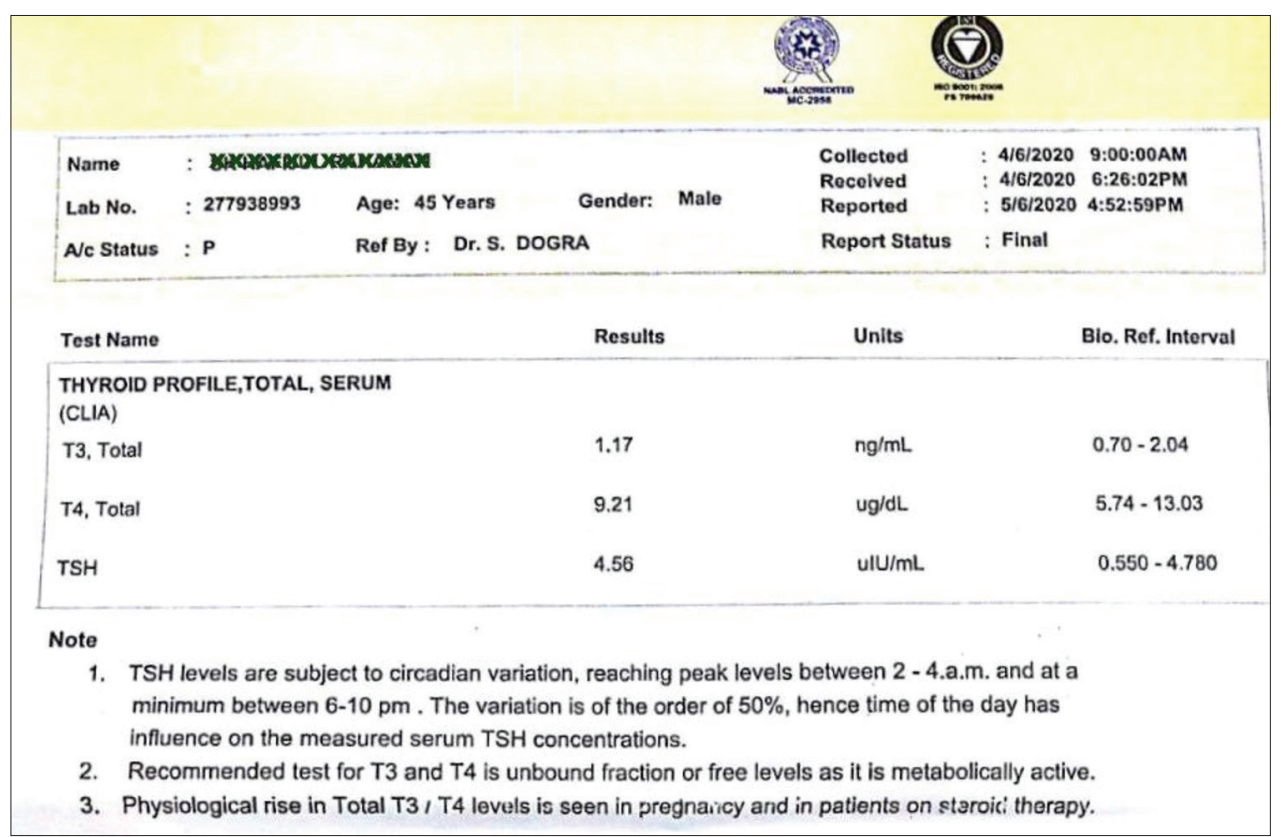

Fig. 6: Examination of TSH (after treatment)

Table 4: Comparison of TSH values

\begin{tabular}{lll}
\hline Cases & $\begin{array}{l}\text { TSH value before } \\
\text { treatment }(\mu \mathrm{u} / \mathrm{ML})\end{array}$ & $\begin{array}{l}\text { TSH value after } \\
\text { treatment }(\mu \mathrm{u} / \mathrm{ML})\end{array}$ \\
\hline Case 1 & 67.39 & 2.63 \\
Case 2 & 9.96 & 5.06 \\
Case 3 & 7.18 & 4.56 \\
\hline
\end{tabular}

Placebo in the form of aqua dist. ( $60 \mathrm{~mL})$. Once in daily $(2 \mathrm{~mL})$ for 1 month. Then, consecutive three follow-ups were done and placebo given. The patient improved gradually physically and mentally, along with reaching normal TSH level.

\section{Follow-ups}

Thirty-six days after the first prescription. Sleepiness improved. All other symptoms remains the same as before. No additional or new symptoms found. Placebo given.

Sixty-eight days after the first prescription. TSH level found normal (Fig. 6). Mental concentration and other physical generals also improved. Placebo given.

Ninety-eight days after the first prescription. The patient feels better No new symptoms appear. Placebo given.

\section{DISCUSSION}

Hypothyroidism is a prevalent endocrine condition. Individuals with this disease are commonly managed through supplementation with synthetic thyroid hormone, with the aim of alleviating symptoms and restoring normal thyroid-stimulating hormone levels [7] Levothyroxine, the treatment of choice, is inexpensive, easy to administer and in most cases restores well-being while normalizing thyroid function. However, $30-50 \%$ of individuals on levothyroxine are either over-treated or undertreated, and others remain dissatisfied with treatment despite achieving thyroid hormone concentrations within the laboratory reference interval [8]. Treatment with constitutional homoeopathic medicine alone or along with levothyroxine leads to the cure of hypothyroidism.

Here, we have compared the levels of TSH, before and after treatment (Table 4). We can see a great improvement in the levels of TSH only with constitutional homeopathic treatment without any other medications.

In this study, we have only used constitutional homeopathic medicine in the treatment of the cases. Previously, few studies were conducted in hypothyroidism titled "Efficacy of homeopathic intervention in subclinical hypothyroidism with or without autoimmune thyroiditis in children: An exploratory randomized control study" [9] and "An openlabel randomized pragmatic exploratory pilot trial to compare the effectiveness of Echinacea Angustifolia $200 \mathrm{cH}$ against individualized homeopathic medicines in hypothyroidism" [10]. We did not find any case series regarding treatment with constitutional homoeopathic medicine. We have got effective result in these cases. Peter Fisher has stated that homeopathy is effective, scientific in treatment of various diseases [11] we, with the results got in these cases, state that homeopathy is efficacious in the treatment of hypothyroidism.

\section{CONCLUSION}

Thus with the effective results (i.e., the reduction in the levels of TSH) obtained in the above cases with the help of homeopathic treatment, we state that homeopathy is efficacious in the treatment of hypothyroidism.

\section{Consent}

The study was verbally explained to the patient, and written consent was obtained. However, the patients were free to withdraw from the study at any time. For the ethical purpose, if any poor prognosis were suspected, then he/she would be referred to a regional hospital.

\section{CONFLICTS OF INTEREST}

The authors have no conflicts of interest.

\section{REFERENCES}

1. Unnikrishnan AG, Kalra S, Sahay RK, Bantwal G, John M, Tewari N. Prevalence of hypothyroidism in adults: An epidemiological study in eight cities of India. Indian J Endocrinol Metab 2013;17:652-47.

2. Bagcchi S. Hypothyroidism in India: More to be done. Lancet Diabetes Endocrinol 2014;2:779.

3. Sood A, Pandav CS, Anand K, Sankar R, Karmarkar MG. Relevance and importance of universal salt iodization in India. Natl Med J India 1997; 10:290-3

4. Kapil U, Saxena N, Ramachandran S, Balamurugan A, Nayar D, Prakash S. 
Assessment of iodine deficiency disorders using the 30 cluster approach in the national capital territory of Delhi. Indian Pediatr 1996;33:1017-3.

5. Sethi B, Barua S, Raghavendra MS, Gotur J, Khandelwal D, Vyas U. The thyroid registry: Clinical and hormonal characteristics of adult Indian patients with hypothyroidism. Indian $\mathrm{J}$ Endocrinol Metab 2017;21:302-7.

6. Gutch M, Philip R, Philip R, Toms A, Saran S, Gupta KK. Skeletal manifestations of juvenile hypothyroidism and the impact of treatment on skeletal system. Indian J Endocrinol Metab 2013;17:S181-3.

7. Brown BT, Bonello R, Pollard H, Graham P. The influence of a biopsychosocial-based treatment approach to primary overt hypothyroidism: A protocol for a pilot study. Trials 2010;11:106

8. Eligar V, Taylor PN, Okosieme OE, Leese GP, Dayan CM. Thyroxine replacement: A clinical endocrinologist's viewpoint. Ann Clin Biochem 2016;53:421-33.

9. Chauhan VK, Manchanda RK, Narangs A, Marwaha RK, Arora S, Nagpal L, et al. Efficacy of homeopathic intervention in subclinical hypothyroidism with or without autoimmune thyroiditis in children: An exploratory randomized control study. Homeopathy 2014;103:224-31

10. Debbarma R, Nayak C, Chattopadhyay A. An open-label randomized pragmatic exploratory pilot trial to compare the effectiveness of Echinacea angustifolia $200 \mathrm{cH}$ against individualized homoeopathic medicines in hypothyroidism. Natl Homoeo Rec 2018;14:24-17.

11. Fisher $\mathrm{P}$. International homoeopathy-science or sectarianism? $\mathrm{Br}$ Homeopath J 1996;85:55-8. 